\title{
Publisher's Note: Redundant Interdependencies Boost the Robustness of Multiplex Networks [Phys. Rev. X 7, 011013 (2017)]
}

Filippo Radicchi and Ginestra Bianconi

(Received 8 February 2017; published 17 February 2017)

DOI: 10.1103/PhysRevX.7.019901

Subject Areas: Complex Systems

This paper was published online on 31 January 2017 with an error in the abstract. The eleventh line of the abstract should read as "adopted percolation model for multiplex networks when the number of layers equals two. For larger number... ." The abstract has been corrected as of 8 February 2017.

Published by the American Physical Society under the terms of the Creative Commons Attribution 4.0 International license. Further distribution of this work must maintain attribution to the author(s) and the published articles title, journal citation, and DOI. 